\title{
Dar bant UVB, UVA1 ve PUVA tedavilerinin melanositik nevusların dermoskopik bulguları üzerine etkileri
}

\author{
Effects of narrowband UVB, UVA 1 and PUVA treatments on \\ dermoscopic features of melanocytic nevi
}

Fulya Karaca, Murat Öztaș, Mehmet Ali Gürer

Gazi Üniversitesi Tıp Fakültesi, Dermatoloji Anabilim Dalı, Ankara, Türkiye

\section{Özet}

Amaç: Ultraviyole (UV) ıșınları melanin sentezini veya melanosit proliferasyonunu arttırarak melanositik nevuslarda dermoskopik değişikliklere neden olabilmektedir. UV ışınlarının dermatolojide foto(kemo)terapi amacıyla yaygın kullanımına rağmen melanositik nevusların dermoskopik özelliklerine etkileriyle ilgili az sayıda çalışma bulunmaktadır. Bu çalışmada dar bant UVB (dbUVB), UVA1, psoralen ve ultraviyole A (PUVA) tedavilerinin melanositik nevusların dermoskopik bulguları üzerine etkilerini saptamayı amaçladık.

Gereç ve Yöntem: Çalışmamıza çeşitli endikasyonlarda fototerapi ünitemizde dar bant UVB tedavisi başlanan 21 hasta, UVA1 tedavisi başlanan 18 hasta ve PUVA tedavisi başlanan 16 hasta olmak üzere toplam 55 hasta dahil edilmiştir. Dar bant UVB grubunda toplam 233, UVA1 grubunda toplam 233 ve PUVA grubunda toplam 229 melanositik nevus, tedavinin 3. ayında dermoskopik değişiklikler yönünden değerlendirilmiştir. Tüm melanositik nevuslar ABCD kuralına göre değerlendirilmiş ve toplam dermoskopi skoru (TDS) hesaplanmıştır.

Bulgular: Dar bant UVB, UVA1 ve PUVA tedavilerinin melanositik nevusların büyüklüğünde istatistiksel olarak anlamlı artış saptanmamıştır. Dar bant UVB, UVA1 ve PUVA tedavileri melanositik nevuslarda izlenen dermoskopik yapılarda istatistiksel anlamlı değişikliğe neden olmuştur. Dar bant UVB grubunda melanositik nevuslarda de novo nokta yapısı izlenmiştir. TDS'de istatistiksel olarak anlamlı derecede değişiklik saptanmamıştır.

Sonuç: dbUVB, UVA1 ve PUVA tedavilerinin melanositik nevusların dermoskopik bulgularında anlamlı derecede değişikliklere neden olmuştur. (Türkderm 2014; 48: 26-30)

Anahtar Kelimeler: Dermoskopi, melanositik nevus, UV, fototerapi

\section{Summary}

Background and Design: Ultraviolet (UV) radiation can affect dermoscopic features of melanocytic nevi by inducing melanin synthesis or melanocyte proliferation. Despite widespread use of UV radiation in the treatment of several skin diseases, there have been only a few studies on its effects on the dermoscopic features of melanocytic nevi. The present study was designed to determine the effects of narrowband UVB, UVA1 and psoralen and UVA (PUVA) treatments on dermoscopic features of melanocytic nevi.

Material and Method: A total of 55 patients, who were referred to our phototherapy unit for the treatment of various skin disorders, were enrolled in this prospective study. Twenty-one patients underwent narrowband UVB, 18 patients underwent UVA 1 and 16 patients underwent PUVA treatment. Dermoscopic images of 233 nevi in narrowband UVB group, 233 nevi in UVA1 group and 229 nevi in PUVA group were evaluated for the alterations in dermoscopic structures at the end of three months. Total dermoscopic scores (TDSs) of melanocytic nevi were calculated according to the $A B C D$ rule.

Results: There was no statistically significant inrease in the size of melanocytic nevi in the therapy groups. Narrowband UVB, UVA1, and PUVA resulted in statistically significant changes in the dermoscopic structures of melanocytic nevi. In narrowband UVB therapy group, de novo dot formation was documented $(p=0.002)$. Only in narrowband UVB group, de novo dot formation was observed. There was no statistically significant change in the mean TDS.

Conclusion: Narrowband UVB, UVA1 and PUVA therapies have significant effects on dermoscopic features of melanocytic nevi. (Turkderm 2014; 48: 26-30)

Key Words: Dermoscopy, melanocytic nevi, UV, phototherapy

Yazışma Adresi/Address for Correspondence: Dr. Fulya Karaca, Gazi Üniversitesi Tip Fakültesi, Dermatoloji Anabilim Dalı, Ankara, Türkiye

Tel.: +90 5053970396 E-posta: fulyacoban@yahoo.com Geliş Tarihi/Received: 03.02.2013 Kabul Tarihi/Accepted: 21.05.2013

Türkderm-Deri Hastalıkları ve Frengi Arșivi Dergisi, Galenos Yayınevi tarafindan basılmıștır.

Turkderm-Archives of the Turkish Dermatology and Venerology, published by Galenos Publishing. 


\section{Giriş}

UV ışınları melanositik nevuslar üzerinde klinik, dermoskopik ve histolojik değişikliklere neden olabilmektedir'. UV'ye maruz kalan nevuslarda histopatolojik olarak hücresel metabolizma ve mitotik aktivite artışı saptanır². Yoğun güneş maruziyeti sonrasında nevus büyüklüğünde artış görülebilir³. Dermoskopi pigmente deri lezyonlarının çıplak gözle görülemeyen morfolojik özelliklerini görünür kılarak tanısal doğruluğu arttıran invaziv olmayan bir tekniktir. Melanositik nevusların dermoskopik paterni mevsimsel değişiklikler gösterebilmekte, yoğun güneş maruziyeti sonrasında pigment ağında genişleme, nokta ve globül sayısında artış izlenebilmektedir ${ }^{4}$.

Elektromanyetik spektrumun bir bölümünü oluşturan ultraviyole ışınlarının dermatolojide foto(kemo)terapi amacıyla yaygın kullanımına rağmen melanositik nevusların morfolojik ve dermoskopik özelliklerine etkileriyle ilgili az sayıda çalışma bulunmaktadı ${ }^{5-8}$.

Bu çalışmada değişik endikasyonlarda dar bant UVB, UVA1 ve PUVA tedavileri başlanan hastaların melanositik nevuslarının tedavi öncesinde ve tedavinin 3. ayında yapılan kontrollerde dermoskopik özelliklerindeki değişikliklerin değerlendirilmesi amaçlanmıştır.

\section{Gereç ve Yöntem}

1 Eylül 2007 ile 31 Mayıs 2009 tarihleri arasında Gazi Üniversitesi Tıp Fakültesi Dermatoloji Anabilim Dalı fototerapi ünitesinde dar bant UVB, UVA1 ve PUVA tedavileri başlanan toplam 55 hasta çalışmaya alındı. Güneş maruziyetini en aza indirmek amacıyla tedaviye Haziran-Temmuz-Ağustos aylarında başlanan hastalar çalışmaya dahil edilmedi. Hastalar çalışma süresince güneş maruziyetinden uzak kalmaları gerektiği konusunda bilgilendirildi. Son 3 ay içerisinde yapay UV'ye maruz kalan hastalar çalışmaya alınmadı.

Dar bant UVB tedavisi alan 21 hastaya UV 7001 (TL-01) Waldmann cihazı ile haftada iki seans tedavi verildi. Birinci ayın sonunda kümülatif doz ortalama $11,1 \pm 7,8 \mathrm{~J} / \mathrm{cm}^{2} ; 3$. ayın sonunda ortalama $35,3 \pm 18,5 \mathrm{~J} / \mathrm{cm}^{2}$ oldu. UVA1 tedavisi alan 18 hastaya Medisun (TL10R) cihazı ile haftada beş seans tedavi verildi. Birinci ayın sonunda kümülatif doz ortalama $411,7 \pm 213,9 \mathrm{~J} / \mathrm{cm}^{2} ; 3$. ayın sonunda ortalama 465,0 $\pm 279,5 \mathrm{~J} / \mathrm{cm} 2$ oldu. PUVA tedavisi alan 16 hastaya ise UV8001 (F85) Waldmann cihazı ile haftada iki seans tedavi verildi. PUVA tedavisi alan hastalara 0,6-0,8 mg/kg/gün dozda 8-MOP'un (Geroxalane ${ }^{\circledR}$ ) oral alımından 2 saat sonra UVA uygulandı. Birinci ayın sonunda kümülatif doz ortalama $22,3 \pm 20,8 \mathrm{~J} / \mathrm{cm}^{2}, 3$. ayın sonunda ortalama $65,6 \pm 31,2 \mathrm{~J} / \mathrm{cm}^{2}$ oldu.

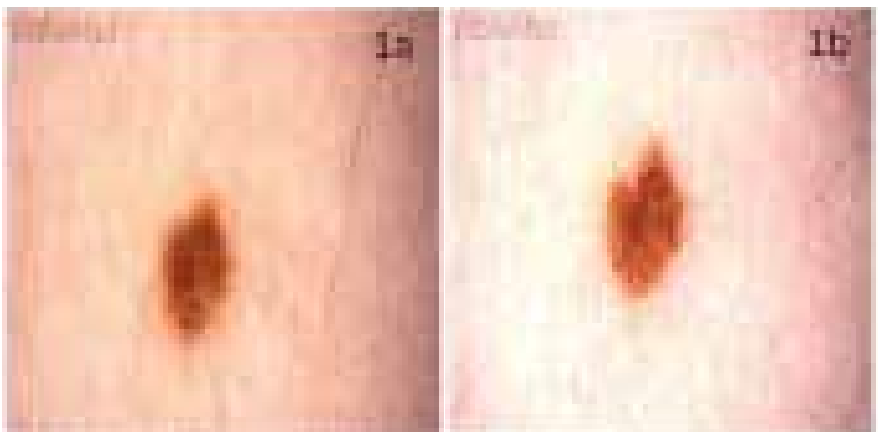

Resim 1. PUVA tedavisi alan hastada pigment ağı alanında artış saptanan nevusun tedavi öncesinde (1a), ve 3. aydaki (1b) dermoskopi görüntüleri
Dar bant UVB tedavisi başlanan 21 hastada toplam 233 melanositik nevus, UVA1 tedavisi başlanan 18 hastada toplam 233 melanositik nevus ve PUVA tedavisi başlanan 16 hastada toplam 229 nevus değerlendirmeye alındı. Değerlendirmeye gövde, alt ve üst ekstremitelerde güneş görmeyen bölgelerde bulunan nevuslar alındı. Çalışmaya dahil edilen melanositik nevusların hiçbiri klinik ve dermoskopik olarak malin özellikler göstermemekteydi.

Çalışma öncesinde Gazi Üniversitesi Tıp Fakültesi Etik Kurulu'ndan çalışma ile ilgili etik kurul onayı ve tüm deneklerden çalışma konusunda bilgilendirildiklerine dair yazılı onay formu alındı.

Tüm melanositik nevusların tedavi öncesi, tedaviye başlandıktan sonraki 3. ayda yapılan dermoskopik değerlendirmelerinde lezyonları 30 kat büyütebilen dijital dermoskop (MoleMax III, Dermalnstruments, Vienna, Austria) kullanıldı. MoleMax III cihazı ile lezyonların görüntüleri JPEG formatında, 640×480 piksel rezolüsyonda ve 24 bit renk derinliğinde kaydedilmektedir. Çalışmamızın sonunda her bir nevusun ardışık iki görüntüsü bilgisayar ekranında yan yana yerleştirilerek; dermoskopik değişiklikler yönünden değerlendirildi.

Melanositik nevusların büyüklükleri Molescore skorlama programıla hesaplandı. Tüm nevuslar için patern analizi ve ABCD (asimetri, sınır, renk, farklı yapısal komponentlerin varlığı) skorlaması yapıldı.

Verilerin analizi SPSS for Windows 11.5 paket programında yapıldı. Gruplar içerisinde dermoskopik yapı ve patern değişimi yönünden istatistiksel olarak izlem zamanlarına göre anlamlı değişimin olup olmadığı McNemar testiyle değerlendirildi. Alanda ve TDS'de zamana göre anlamlı değişimin olup olmadığı ise Friedman testiyle araştııılı. $\mathrm{P}<0,05$ için sonuçlar istatistiksel olarak anlamlı kabul edildi. Olası tüm çoklu karşılaştırmalarda Tip I hatayı kontrol altına alabilmek için Bonferroni düzeltmesi yapıldı.

\section{Bulgular}

Çalışmamıza dar bant UVB tedavisi başlanan 21 hasta; UVA1 tedavisi başlanan 18 hasta; PUVA tedavisi başlanan 16 hasta olmak üzere toplamda 55 hasta alındı. Hastaların demografik özellikleri Tablo 1'de gösterilmiştir. Dar bant UVB grubunda 233, UVA1 grubunda 233, PUVA grubunda 229 olmak üzere toplam 695 melanositik nevus değerlendirildi.

Dar bant UVB, UVA1 ve PUVA tedavisi alan hasta gruplarında melanositik nevusların ortalama alan ölçümlerinde istatistiksel olarak anlamlı artış olmadı (Tablo 2).

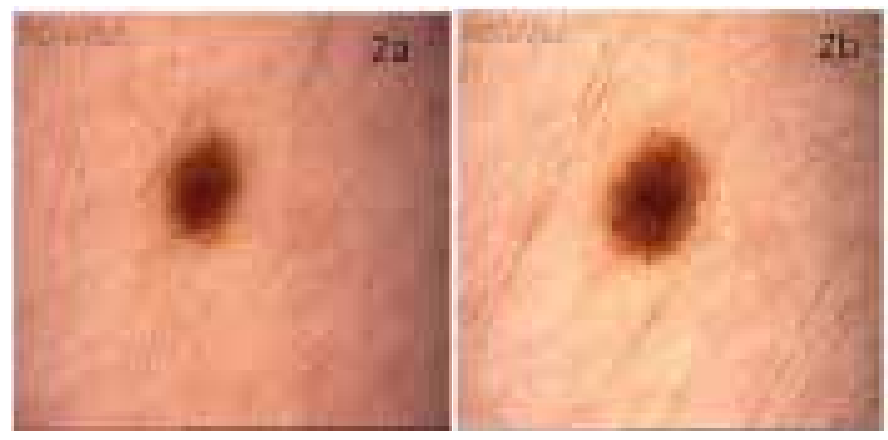

Resim 2. Dar bant UVB tedavisi alan hastada periferik globüllerde artış saptanan nevusun tedavi öncesinde (2a) ve 3. aydaki (2b) dermoskopi görüntüleri 
Dar bant UVB, UVA1 ve PUVA tedavileri 3. ayda dermoskopik yapılardaki değişiklikler (homojen alanda artma/azalma, nokta ve globül sayısında artma/azalma, pigment ağı alanında artma/azalma, dallanmış uzantılarda artma/azalma) birlikte değerlendirildiğinde

\section{Tablo 1. Hastaların demografik özellikleri}

\begin{tabular}{|l|c|c|c|}
\hline & dbUVB (n=21) & UVA1 (n=18) & PUVA (n=16) \\
\hline Yaş & $35,9 \pm 13,6$ & $44,9 \pm 10,5$ & $36,4 \pm 13,3$ \\
\hline Cinsiyet & \multicolumn{3}{|l|}{} \\
\hline Erkek & $9(\% 42,9)$ & $7(\% 38,9)$ & $1(\% 6,3)$ \\
\hline Kadın & $12(\% 57,1)$ & $11(\% 61,1)$ & $15(\% 93,8)$ \\
\hline Deri Tipi & \multicolumn{5}{|l|}{} \\
\hline Tip II & $8(\% 38,1)$ & $5(\% 27,8)$ & $4(\% 25,0)$ \\
\hline Tip III & $12(\% 57,1)$ & $10(\% 55,6)$ & $10(\% 62,5)$ \\
\hline Tip IV & $1(\% 4,8)$ & $3(\% 16,7)$ & $2(\% 12,5)$ \\
\hline
\end{tabular}

Tablo 2. Melanositik nevusların alan ölçümleri

\begin{tabular}{|l|l|l|l|}
\hline Gruplar & Tedavi Öncesi $\left.\mathbf{( m m}^{\mathbf{2}}\right)$ & $\mathbf{3 .} \mathbf{A y}\left(\mathbf{m m}^{\mathbf{2}}\right)$ & $\mathbf{p}^{\mathbf{a}}$ \\
\hline dbUVB & $2,54 \pm 3,33$ & $2,57 \pm 3,43$ & 0,507 \\
\hline UVA1 & $2,73 \pm 2,87$ & $2,63 \pm 2,47$ & 0,423 \\
\hline PUVA & $3,07 \pm 4,12$ & $3,18 \pm 4,33$ & 0,018 \\
\hline
\end{tabular}

a Bonferroni Düzeltmesine göre $p<0,017$ için sonuçlar istatistiksel olarak anlamlı kabul edildi.

Tablo 3. Tedavi gruplarında dermoskopik yapılarda saptanan değişiklikler yönünden nevusların dağılımı

\begin{tabular}{|c|c|c|c|}
\hline & $\begin{array}{l}\text { dbUVB } \\
(n=233)\end{array}$ & $\begin{array}{l}\text { UVA1 } \\
(n=233)\end{array}$ & $\begin{array}{l}\text { PUVA } \\
(n=229)\end{array}$ \\
\hline \multicolumn{4}{|l|}{ 3. Ayda } \\
\hline $\begin{array}{l}\text { Dermoskopik yapı } \\
\text { değişikliği yok }\end{array}$ & $170(\% 73,0)$ & $174(\% 74,7)$ & $157(\% 68,6)$ \\
\hline $\begin{array}{l}\text { Dermoskopik yapı } \\
\text { değişikliği var }\end{array}$ & $63(\% 27,0)$ & $59(\% 25,3)$ & $72(\% 31,4)$ \\
\hline$p^{a}$ & $<0,001$ & $<0,001$ & $<0,001$ \\
\hline
\end{tabular}

istatistiksel olarak anlamlı derecede değişikliğe neden oldu $(p<0,001)$ (Tablo 3). En sık görülen değişiklik ise nokta ve globül sayısındaki artış olmuştur (Tablo 4).

Dar bant UVB tedavisi alan 21 hastanın 15'inde toplam 63 nevusda dermoskopik yapılarda değişiklik saptandı. Hastalar incelendiğinde en fazla değişiklik saptanan hastanın 39 nevusunun 12'sinde değişiklik gözlendi. Üç hastada ise birer nevusda değişiklik mevcuttu.

UVA1 grubunda ise 18 hastanın 14'ünde olmak üzere toplam 59 melanositik nevusda dermoskopik yapılarda değişiklik görüldü. Bu grupta en fazla değişiklik görülen hastanın 24 nevusunun $18^{\prime}$ inde değişiklik izlendi.

PUVA tedavisi alan hasta grubunda ise 16 hastanın 12'sinde toplam 72 melanositik nevusda değişiklik gözlendi. Bu grupta değişiklik saptanan nevus sayısı bir hastada en fazla 14 nevusda (35 nevusun 14'ünde değişiklik mevcut) saptandı. Dermoskopik yapılarda değişiklik saptanan nevus sayılarının oranları ve kişilere göre dağılımında tedavi grupları arasında istatistiksel olarak anlamlı fark yoktu $(p=0,319)$.

PUVA tedavisi alan hastada pigment ağı alanında artış saptanan nevusun dermoskopik görüntüleri Resim 1'de, dar bant UVB tedavisi alan hastada periferik globüllerde artış saptanan nevusun dermoskopik görüntüleri ise Resim 2'de verilmiştir. Ayrıca dar bant UVB tedavi grubunda, tedavi öncesine göre de novo nokta yapısı izlenen melanositik nevus sayısında istatistiksel olarak anlamlı artış saptandı $(p=0,002)$.

Tüm melanositik nevuslar dermoskopik olarak ABCD kriterlerine göre değerlendirildi ve TDS hesaplandı. Tüm melanositik nevusların hepsi benin melanositik lezyon olarak değerlendirildi. Üçüncü ayın sonunda ortalama TDS değerlerinde istatistiksel olarak anlamlı değişiklik saptanmadı (Tablo 5).

\section{Tartışma}

Ultraviyole (UV) ışınları melanin sentezini arttırarak veya melanosit proliferasyonuna sebep olarak melanositik nevuslarda klinik, histolojik ve dermoskopik değişikliklere neden olabilmektedir ${ }^{1,6-9}$. Derviş ve ark. PUVA tedavisi alan 14 hastada toplam 28 melanositik nevus değerlendirmişler, tedavilerinin 3. ayında melanositik nevusların çapında artış saptamışlardır . Başka bir çalışmada Kılınç-Karaarslan ve

Tablo 4. Dar bant UVB, UVA1 ve PUVA tedavileri sonrasında saptanan dermoskopik değişiklikler

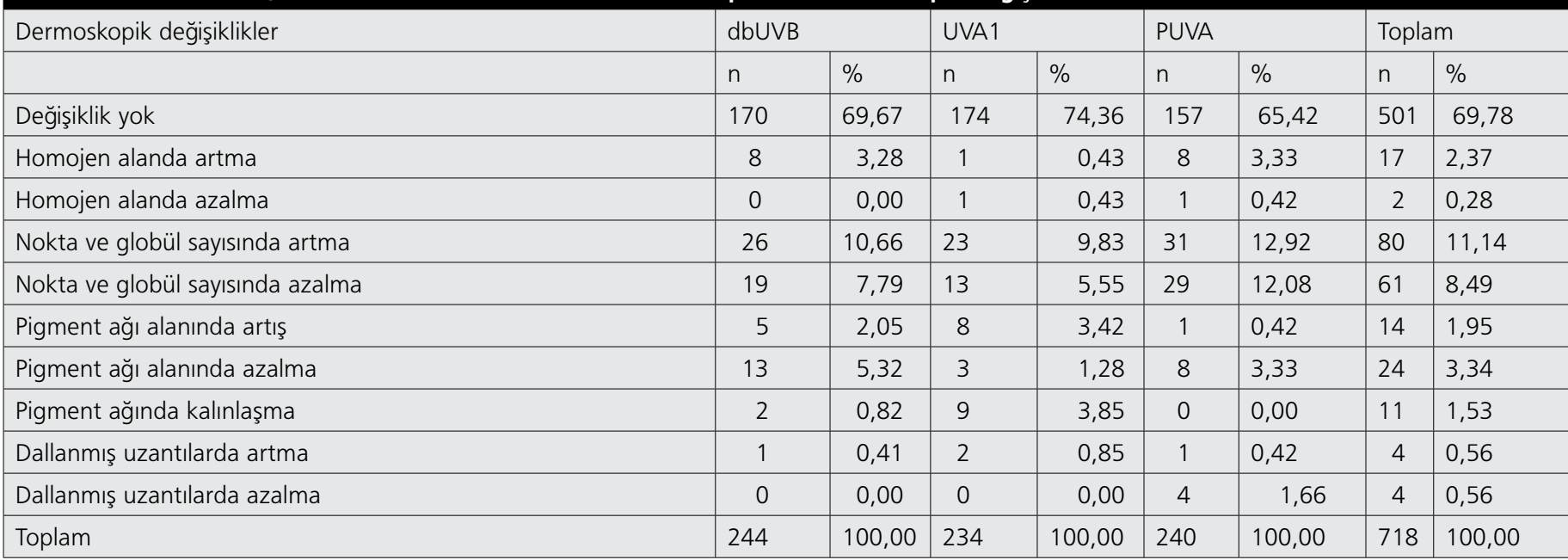


Tablo 5. Tedavi gruplarında melanositik nevusların TDS değerleri

\begin{tabular}{|l|l|l|l|}
\hline Gruplar & Tedavi Öncesi & 3. Ay & pa \\
\hline dbUVB & $1,56 \pm 0,57$ & $1,59 \pm 0,57$ & 0,062 \\
\hline UVA1 & $1,65 \pm 0,76$ & $1,66 \pm 0,77$ & 0,447 \\
\hline PUVA & $1,80 \pm 0,73$ & $1,81 \pm 0,72$ & 0,882 \\
\hline
\end{tabular}

a Bonferroni Düzeltmesine göre $p<0,017$ için sonuçlar istatistiksel olarak anlamlı kabul edildi.

ark.'ı da PUVA tedavisi alanlar için ortalama 6 hafta, dar bant UVB için ortalama 9 hafta süren tedavi sonrasında melanositik nevusların alanında istatistiksel olarak anlamlı artış saptamışlardır ${ }^{5}$. Manganoni ve ark.'। ise eritem oluşturmayan dozlarda haftada üç kez UVA1 ve dar bant UVB uygulamalarının 1. ayın sonunda melanositik nevusların çapını arttırdığını bildirmişlerdir ${ }^{8}$ Çalışmamızda ise toplam 695 melanositik nevus değerlendirilmiş ve dar bant UVB, UVA1 ve PUVA tedavilerinde nevus alan ölçümlerinde istatistiksel olarak anlamlı değişiklik görülmemiştir.

Ultraviolet (UV) ışınları melanin sentezini ve melanosit proliferasyonunu arttırarak melanositik nevuslarda dermoskopik olarak yeni yapıların gelişmesine sebep olabildiği gibi mevcut olan yapıların sayısında, büyüklüğünde de değişikliklere neden olabilmektedir, ${ }^{1,6-9}$. Melanositik nevusların yaz aylarındaki dermoskopik incelemelerinde, kış aylarına göre pigment ağında kalınlaşma ve nokta sayısında artış olduğu gösterilmiştir ${ }^{9}$. PUVA tedavisinin etkilerinin araştırıldığı başka bir çalışmada da 3. ayın sonunda pigment ağında genişleme, fokal dallanmış uzantıların oluşması ve kahverengi globüllerin sayı ve büyüklüğünde artış gibi değişiklikler saptanmıştır ${ }^{6}$. Manganoni ve ark.'I dar bant UVB veya UVA1'e maruz kalan melanositik nevusların dermoskopik özelliklerinde istatistiksel olarak anlamlı değişikliklerin olduğunu bildirmişlerdir ${ }^{10}$. HofmannWellenhof ve ark.'ı 8 hafta süren UVB tedavisi sonunda pigment ağında genişleme ve kahverengi globüllerde artış bildirmişler ${ }^{7}$. Lin ve ark. da 440 nevusu değerlendirdikleri çalışmada dar bant UVB fototerapisinin dermoskopik olarak nokta ve globül sayısında artışa ve retiküler ağ yapısında bulanıklaşma ve birleşmelere neden olduğunu göstermişlerdir ${ }^{11}$. Çalışmamızda da dar bant UVB, UVA1 ve PUVA tedavilerinin melanositik nevuslarda izlenen dermoskopik yapılarda istatistiksel olarak anlamlı değişikliklere neden oldukları görülmüştür. Tüm tedavi gruplarında saptanan en sık değişiklik ise nokta ve globül sayısındaki artış olmuştur. Ayrıca sadece dar bant UVB grubunda de novo nokta oluşumu gözlenmiştir. Noktalar histopatolojik olarak stratum korneum, epidermisin üst tabakaları veya dermoepidermal bileşkedeki fokal melanin birikimini göstermektedir. UVB'nin dalga boyunun UVA'ya göre daha kısa olması ve deride etkilerinin daha yüzeysel olması nedeniyle, dar bant UVB grubunda de novo nokta oluşumunun gözlendiği düşünülmektedir. Literatürde yoğun güneş maruziyetinin de novo pigment ağı, nokta ve globül oluşumu gibi dermoskopik yapılarda değişikliklere neden olduğu bildirilmiştir ${ }^{4}$. Başka bir çalışmada Kılınç-Karaarslan ve ark.'ı dar bant UVB ve PUVA'nın etkilerini karşılaştırdıklarında sadace dar bant UVB grubundaki melanositik nevuslarda nokta ve globül sayısında anlamlı artış gözlemişler ${ }^{5}$. Çalışmamızda tedavi grupları arasında dermoskopik özelliklerde değişiklik saptanan nevus dağılmı yönünden ise fark saptanmamıştır. Manganoni ve ark.'ı da benzer şekilde UVA1 ve dar bant UVB tedavisi alan hasta grupları arasında dermoskopik değişikler yönünden fark saptamamışlardır ${ }^{10}$
Ultraviyole (UV) ışınları maruziyetinin melanom gelişimindeki en önemli çevresel faktör olduğu bilinmektedir. Epidemiyolojik çalışmalar özellikle çocukluk ve adolösan dönemde aralıklı yoğun güneş maruziyetinin, güneş yanıklarının melanom etiyolojisindeki önemini göstermektedir. Fakat melanom patogenezinde UVR'nin hangi dalga boyunun primer rol oynadığı bilinmemektedir. Güneş yanıklarından temel olarak UVB'nin sorumlu olması ve güneş yanıkları ile kutanöz melanom gelişimi arasındaki ilişki kutanöz melanoma sebep olan ışık spektrumunun esas olarak UVB olduğunu düşündürmektedir ${ }^{12}$. Bununla birlikte UVA'nın da etkili olduğunu gösteren kanıtlar bulunmaktadır. Son yıllarda güneşten koruyucuların yaygın kullanımıyla ilişkili olarak melanom insidansının artı̆̆ını gösteren çalışmalar bulunmaktadır. Güneşten koruyucu kullanımı ile eritemojenik olan UVB'ye korunma sağlanırken, güneş altında geçirilen zamanın artmasına bağlı olarak UVA maruziyeti artmaktadır ${ }^{13}$. Epidemiyolojik çalışmalar da bronzlaştııı kabinleri kullananlarda melanom insidansının arttığını ve UVA'nın melanom gelişiminde önemli etkilerinin bulunabileceğini göstermektedir. PUVA ve UVB gibi yapay ışık kaynaklarının da melanom gelişiminde etkilerinin bulunduğuna dair kanıtlar bulunmaktadır ${ }^{14}$. Çalışmamızda dar bant UVB, UVA1 ve PUVA tedavilerinin melanositik nevuslar üzerinde displastik etkilerinin olup olmadığını değerlendirmek amacıyla ABCD kuralından yararlanıımıştır. $A B C D$ kriterlerine göre lezyonlar değerlendirilerek puanlama yapıldığında melanositik nevusların hepsinde toplam dermoskopik skorun 1 ile 4,75 arasında ve benin melanositik lezyon olduğu görülmüştür. Dar bant UVB, UVA1 ve PUVA tedavileri melanositik nevusların ortalama TDS'lerinde istatistiksel olarak anlamlı farka yol açmamıştır. Stern ve ark. PUVA tedavisi alanlarda UVA kümülatif dozu ile orantılı olarak kutanöz melanom gelişme riskinin arttığını, özellikle 250 seans ve üzerinde tedavi alanlarda riskin daha yüksek olduğunu bildirmişlerdir ${ }^{15}$. Çalışmamızdaki takip süresinin daha kısa olması nedeniyle melanositik nevuslar üzerinde displastik etkiler saptanmamış olabilir. Uzun süreli tedavi alanlarda melanom açısından dikkatli takip yapılmalıdır.

Sonuç olarak çalışmamızda dar bant UVB, UVA1 ve PUVA tedavilerinin dermoskopik yapılarda değişikliklere neden olduğu, özellikle dar bant UVB tedavisinde yeni nokta yapılarının geliştiği görülmüştür. Bu bulgular fototerapi alan hastalarda UV'nin melanositik nevuslar üzerindeki olası displastik etkileri yönünden dikkate alınması gerektiğini göstermektedir.

\section{Kaynaklar}

1. Hofman-Wellenhof R, Soyer HP, Wolf IH, Smolle J, Reischle S, Rieger E, Kenet $\mathrm{RO}$, Wolf $\mathrm{P}$, Kerl $\mathrm{H}$ : Ultraviolet radiation of melanocytic nevi: a dermoscopic study. Arch Dermatol 1998;134:845-50.

2. Pawlowski A, Pawlowski MD, Lea PJ: Effects of UV radiation on the ultrastructure of human common pigmented naevi and lentigines. Acta Derm Venereol 1991;71:113-7.

3. Dobrosavljevic D, Brasanac D, Apostolovic M, Medenica L: Changes in common melanocytic naevi after intense sun exposure: digital dermoscopic study with a 1-year follow-up. Clin Exp Dermatol 2009;34:672-8.

4. Stanganelli I, Bauer P, Bucchi L, Serafini M: Critical effects of intense sun exposure on the expression of epuliminescence microscopy features of acquired melanocytic nevi. Arch Dermatol 1997;133:979-82.

5. Kilinc Karaarslan I, Teban L, Dawid M, Tanew A, Kittler H: Changes in the dermoscopic appearance of melanocytic naevi after photochemotherapy or narrow-band ultraviolet B phototherapy. J Eur Acad Dermatol Venereol 2007;21:526-31.

6. Dervis $E, K o c ~ K$, Karaoglu A: Influence of PUVA therapy on dermoscopic features of acquired melanocytic nevi. Eur J Dermatol 2004; 14:230-4 
7. Hofmann-Wellenhof $R$, Wolf $P$, Smolle J, Reimann-Weber $A$, Soyer HP Kerl H: Influence of UVB therapy on dermoscopic features of acquired melanocytic nevi. J Am Acad Dermatol 1997;37:559-63.

8. Manganoni AM, Tucci G, Venturini M, Farisoglio C, Calzavara-Pinton PG: Repeated equally effective suberythemogenic exposures to ultraviolet (UV)A1 or narrowband UVB induce similar changes of the dermoscopic pattern of acquired melanocytic nevi that can be prevented by high-protection UVA-UVB sunscreens. I Am Acad Dermatol 2008;58:763-8.

9. Stanganelli I, Rafanelli S, Bucchi L: Seasonal prevalence of digital epiluminescence microscopy patterns in acquired melanocytic nevi. J Am Acad Dermatol 1996;34:460-4.

10. Manganoni AM, Rossi MT, Sala R, et al: Dermoscopic, histological and immunohistochemical evaluation of cancerous features in acquired melanocytic nevi that have been repeatedly exposed to UVA or UVB. Exp Dermatol 2012;21:86-90.

11. Lin CY, Oakley A, Rademaker M, Hill S, Yung A: Effect of narrowband ultraviolet B phototherapy on melanocytic naevi. Br J Dermatol 2013;168:815-9.

12. Elwood JM, Jopson J: Melanoma and sun exposure: an overview of published studies. Int J Cancer 1997;73:198-203.

13. Ley RD: Ultraviolet radiation A-induced precursors of cutaneous melanoma in Monodelphis domestica. Cancer Res 1997;57:3682-4.

14. Wang SQ, Setlow R, Berwick M, Polsky D, Marghoob AA, Kopf AW, Bart RS: Ultraviolet A and melanoma: A review. J Am Acad Dermatol 2001;44:837-46.

15. Stern RS, Nichols KT, Väkevä LH: Malignant melanoma in patients treated for psoriasis with methoxsalen(psoralen) and ultraviolet $A$ radiation (PUVA). N Engl J Med 1997;336:1041-5. 